\title{
Potential of Renewable Energy Sources usage in an energy demand of a single-family houses neighbourhood, constituting an Energy Cluster - a case study
}

\author{
Marcin Zygmunt ${ }^{1, *}$, Dariusz Gawin ${ }^{1}$ \\ ${ }^{1}$ Lodz University of Technology, Faculty of Civil Engineering, Architecture and Environmental Engineering, Lodz, Poland
}

\begin{abstract}
Worldwide policy referring to global warming and air pollution assumes several main guidelines, in which Renewable Energy Sources (RES) usage simultaneously with limitation of fossil fuels in energy production seems to be a major goal. Nowadays, the continuous growth of RES usage within final energy consumption is becoming an obvious part of many country's development. Adding to that relentless pursuit for improvement of building energy efficiency results in prediction, that in nearest future one should expect the development of advanced city-scale areas constituting an Energy Cluster. The paradigm of Energy Cluster (EC) allows us to define an energy flexibility neighbourhood. This article presents the results of energy analysis of a model neighbourhood of single-family houses with possible usage of RES. The neighbourhood constituting an EC was defined considering the Polish household sector statistical study. The analyzed area consists of representative single-family houses of Poland, characterized by different built periods, building shape and geometry as well as building enclosure parameters. Within the analysis, a detailed examination of a defined EC was performed by means of TEAC - computer tool developed by authors. TEAC is based on the results of energy simulations obtained by means of Energy Plus software and Artificial Neural Network (ANN) usage. Artificial Intelligence (AI) was used for energy demand predictions of buildings. Among possible RES a detailed analysis of solar and wind energy usage was performed. As a result, we obtained an hourly energy demand space- and time distribution, RES outputs, ecological analysis concerning greenhouse gasses emission and profitability analysis of proposed modernizations for the neighbourhood.
\end{abstract}

\section{Introduction}

Presently, many energy and climate regulations have been legislated. Introduced adjustments are a response to a global problem concerning environmental aspects, especially countering global warming. Each country has its own legislative agenda related to energy and environmental aspects, but all of them have common goals - sustainable, energy-independent and proecological development.

Amongst main ecological sectors, households play a crucial role towards sustainability. The building sector has a huge potential to improve energy performance considering traditional and novel buildings refurbishments methods. Nowadays, the traditional improvement of building enclosure thermal properties is no longer a sufficient way for energy efficiency improvement. It is necessary to consider the application of Renewable Energy Sources (RES) as well as advanced building management systems for interior conditions control. Moreover, e-mobility is becoming more and more popular, especially in urban areas. Hence it is necessary to analyse altogether energy profiles of residential buildings, potential outputs from RES and electric vehicles charging systems. Finally, previous development of building sector allows predicting a huge application of self-learning control systems (AI usage) within dwellings. Low energy buildings of the future will be dynamically operated providing a highly sustainable environment.

Residential buildings are typically a major part of a large-scale built environment constituting a city-district. Analyses related to building sector energy should be pursued by means of a holistic approach - it is necessary to analyze whole areas. Due to such type of energy-related analyses, it is possible to obtain a realistic assessment for some proposed modernizations. Additionally, those kinds of analyses are acquiescent with an EC paradigm.

The aim of the performed study is an energy analysis of a model residential neighbourhood, constituting an energy cluster. The analyzed model EC is an area, consisting of representative single-family houses of Poland. The analysis was performed by means of the computer tool named TEAC, developed by Authors. The software allows for energy-, ecological- and environmental analyses of a defined cluster, including energy demand reduction and peak demand clipping, the potential for RES application, emissions analysis and profitability of the proposed modernizations. Those kinds of analyses are highly needed for stable and optimal management of the electrical grid.

\footnotetext{
* Corresponding author: marcin.zygmunt@p.p.lodz.pl
} 


\section{Methods and problem definition}

The motivation of the performed study was an unsatisfactory energetic condition of the overall Polish household sector. Within the sector, single-family houses represent a major part and they are responsible for approx. $30 \%$ of national energy consumption [1]. Furthermore, energy efficiency improvements are relatively easy to apply in single-family houses [2]. Moreover, singlefamily houses are typically placed within residential areas which are perfect for various analyses following the EC paradigm. The analyses might refer to economic-, energyand environmental aspects of whole regions.

Buildings parameters were assumed following Polish building typology [3], in which single-family houses were divided into 7 types, based on built periods and energy characteristics. The parameters of representative singlefamily houses of Poland are summarized in Table 1. It can be clearly seen from the statistical data, that nowadays bigger houses with more windows are constructed, comparing to the past. Also, buildings' shape factor (A/V) is decreasing - modern single-family houses of Poland are characterized with a more compact design. It can be also pointed out that the first significant improvement of building enclosure thermal parameters occurred after 1992 with the second meaningful breakthrough after 2003.

Unfortunately, the published data is limited hence it is necessary to assume some simplifications when defining computer models for energy simulations. For purposes of the performed study, it was assumed, that all buildings have a squared plan, with two occupied floors, unoccupied attic with a gable-type roof (two-side roof), inclined by 30 degrees. Further assumptions were related to buildings fenestration, its placements and dimensions windows were set directly in the middle of available exterior wall area, $0.8 \mathrm{~m}$ above the ground floor level with the height of $1.4 \mathrm{~m}$.

Using all available buildings' data and the established assumptions, 7 computer models were defined by means of Energy Plus software [4]. Energy Plus software is a world-leading computer code used for complex buildings' energy-related simulations. Simulations are performed with at least hourly calculation step with the usage of detailed weather files (Typical Meteorological Year files). Energy Plus is, in general, a simulation engine, with a modular structure - it has three basic components: the simulation manager, the heat balance simulation module and the building systems simulation module. Analyses performed using Energy Plus can be successfully used in various comprehensive studies related to buildings, especially focused on thermalrenovations [5], HVAC systems and facilities [6], interior climate conditions [7] or buildings energy flexibility improvement [8]. Some initial analyses of the performed computer simulations (single object approach) were presented in section 2.1 .

To perform a residential area analysis, it is crucial to define a built environment, focusing on buildings' space distributions and their mutual impact. Neighbourhoods consist of multiple buildings having a defined energy demand, mainly dependent on exterior climate conditions and resident habits and needs. Furthermore, zone energy consumption will vary depending on multiple additional factors, such as localization, a period of the year or urban density. Nevertheless, energy-related analyses of a singlefamily house's neighbourhood are a base for smart grid approach researches [9]. Smart grid areas development is highly important due to the potentially high impact on the future shape of national energy consumption.

Whenever any modernization is applied within an analysed area and it resulted in an improvement of energy efficiency, it might be a basis to establish an EC [10, 11]. Energy Cluster encompasses all the actions resulting in improvement of energy efficiency and electrical grid safety of the area. All analysed aspects of the energy cluster might be grouped into some main spheres, which may be analysed together or separately (see Fig. 1.). In this paper, a model neighbourhood, consisting of several representative single-family houses of Poland, was studied, including energy and environment potential improvement analysis following the EC paradigm. Further description of the examined neighbourhood is presented in section 3 .

Table 1. Geometry parameters and energy characteristics of Polish representative single-family houses (source: [3])

\begin{tabular}{|c|c|c|c|c|c|c|c|c|c|}
\hline $\begin{array}{c}\text { Building } \\
\text { type }\end{array}$ & $\begin{array}{c}\mathbf{A}_{\mathbf{f}} \\
{\left[\mathbf{m}^{\mathbf{2}}\right]}\end{array}$ & $\begin{array}{c}\mathbf{V} \\
{\left[\mathbf{m}^{\mathbf{3}}\right]}\end{array}$ & $\begin{array}{c}\mathbf{A}_{\text {win,tot }} \\
{\left[\mathbf{m}^{\mathbf{2}}\right]}\end{array}$ & $\begin{array}{c}\mathbf{A} / \mathbf{V} \\
{[\mathbf{1} / \mathbf{m}]}\end{array}$ & $\begin{array}{c}\mathbf{U}_{\mathbf{w}} \\
{\left[\mathbf{W} / \mathbf{m}^{\mathbf{2}} \mathbf{K}\right]}\end{array}$ & $\begin{array}{c}\mathbf{U}_{\mathbf{r}} \\
{\left[\mathbf{W} / \mathbf{m}^{2} \mathbf{K}\right]}\end{array}$ & $\begin{array}{c}\mathbf{U}_{\text {win }} \\
{\left[\mathbf{W} / \mathbf{m}^{\mathbf{2}} \mathbf{K}\right]}\end{array}$ & $\begin{array}{c}\mathbf{C O P} \\
{[-]}\end{array}$ & Fuel \\
\hline $\mathbf{T 1}^{(*)}$ & 72.00 & 180.50 & 13.00 & 1.19 & 1.70 & 0.85 & 5.15 & 0.59 & coal \\
\hline $\mathbf{T 2}^{(*)}$ & 98.20 & 245.50 & 20.60 & 1.16 & 1.70 & 0.75 & 5.15 & 0.59 & coal \\
\hline $\mathbf{T 3}^{(*)}$ & 128.60 & 330.80 & 23.10 & 1.06 & 1.18 & 0.65 & 2.75 & 0.59 & coal \\
\hline $\mathbf{T 4}^{(*)}$ & 140.30 & 408.00 & 24.10 & 0.96 & 1.40 & 0.50 & 2.70 & 0.86 & gas \\
\hline $\mathbf{T 5}^{(*)}$ & 160.10 & 448.30 & 35.70 & 0.97 & 0.50 & 0.50 & 1.70 & 0.87 & gas \\
\hline $\mathbf{T 6}^{(*)}$ & 175.50 & 501.20 & 38.40 & 0.95 & 0.28 & 0.40 & 1.30 & 0.87 & gas \\
\hline $\mathbf{T 7}^{(*)}$ & 188.20 & 540.00 & 47.40 & 0.94 & 0.29 & 0.35 & 1.20 & 0.87 & gas \\
\hline
\end{tabular}

(*) different building types, related to build period: T1: before 1945; T2: 1946-1966; T3: 1967-1985; T4: 1986-1992; T5: 1993-2002; T6: 2003-2008; T7: after 2009; $\mathbf{U}_{\mathbf{w}}$ : thermal transmittance of exterior walls; $\mathbf{U}_{\mathbf{r}}$ : thermal transmittance of roofs; $\mathbf{U}_{\text {win: }}$ thermal transmittance windows; $\mathbf{C O P}_{\mathbf{H}}$ : heating system coefficient of performance 


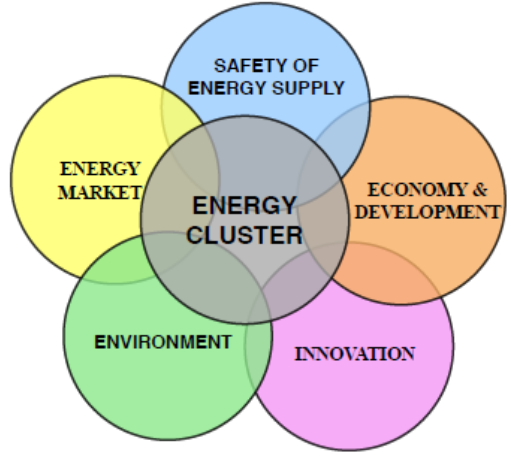

Fig. 1. Energy Cluster fields - concept (own study)

Performing an analysis of a whole residential area means implicitly to make use of some computer tools. Despite there is a large variety of available software for the mentioned purposes (e.g. CitySim [13] or City Energy Analyst [14]), all of them include multiple simplifications within buildings description, which might cause a high uncertainty of the results obtained. Hence, we decided to develop a special software dedicated to energy and ecological analyses of residential areas.

The computer Tool for Energy Efficiency Analysis of an Energy Cluster (TEAC) is a special software developed for various analyses of Polish single-family houses stock. $T E A C$ is based on the results of about 100 thousand detailed computer simulations performed by means of Energy Plus software - it allows to obtain sufficiently accurate, time-related results. A more detailed description of the TEAC software is presented in [12]. The flow chart of the analysis procedure, with highlighted fields covered by the software, is shown in Fig. 4. TEAC software has several modules (most of them written in Python programming language), in which the main ones are related to neighbourhood definition, parametric simulations, ANN predictions and analyses, and finally the presentation of results.

The most important module of TEAC software uses Artificial Neural Networks (ANNs) $[15,16]$ for heating demand predictions. The Lavenberg-Marquardt (LM) method [17] was applied, with a simple structure of the network, consisted of 12 input neurons, 12 neurons within one hidden layer and one output neuron. ANN analyses were performed for 3 different periods (monthly, daily, hourly) and checked by means of regression plots for the test set of data. A very good match was observed for monthly and daily predictions -regression coefficient $R$ for test data equals to 0.9958 and 0.9808 , accordingly, and a good one for hourly study $-R$ equals to 0.8903 (see Fig. 2.). Accuracy of the trained network was checked by additional validation of predicted heating demands with the results obtained by means of Energy Plus software. The defined network is capable to predict heating demand of Polish representative single-family houses with sufficient accuracy.

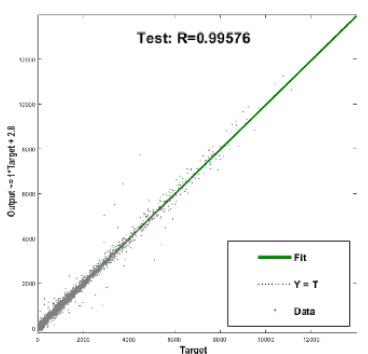

(a)

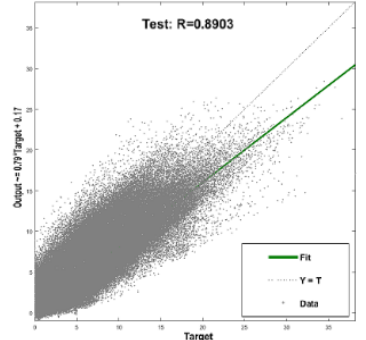

(b)
Fig. 2. Regression plot for the test data of ANN analysis for (a) monthly and (b) hourly calculation periods

It is important to notice that whenever new analyses are performed, the TEAC software database might be further updated. Currently, the TEAC software database consists of 100800 simulation outputs, including:

- 10 different locations of Poland (exterior climate conditions);

- 7 models of representative single-family houses of Poland;

- 8 different buildings orientations;

- 10 variants of buildings positioning within area;

- 9 variants of boiler efficiency (traditional heating system);

- 2 variants of GSHP application (data from the producer's catalogues)

In $T E A C$ software it is possible to define an analysed neighbourhood following 3 different space distributions of buildings of different properties (construction time) (Fig. 3.):

- random (DT1),

- based on old cities growth plan (DT2),

- based on streets grid (DT3).

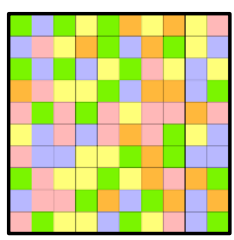

(a)

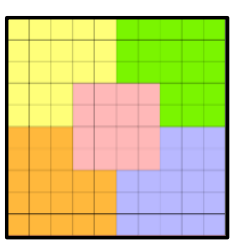

(b)

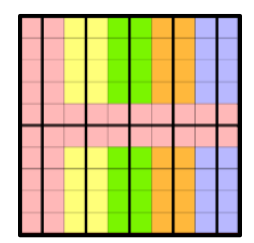

(c)
Fig. 3. Available neighbourhood built environments schemas by means of TEAC software: (a) DT1; (b) DT2; (c) DT3; each colour represents one group of buildings

During the analysis of a considered EC, it is possible to choose an output format for presenting results of a performed study. Renewable Energy Sources (RES) application is one of the available modules in TEAC software - solar and wind energy usage for buildings purposes is assumed. Selected types of RES are commonly used for buildings energy supply, especially solar energy [18].

\footnotetext{
* Corresponding author: marcin.zygmunt@p.lodz.pl
} 


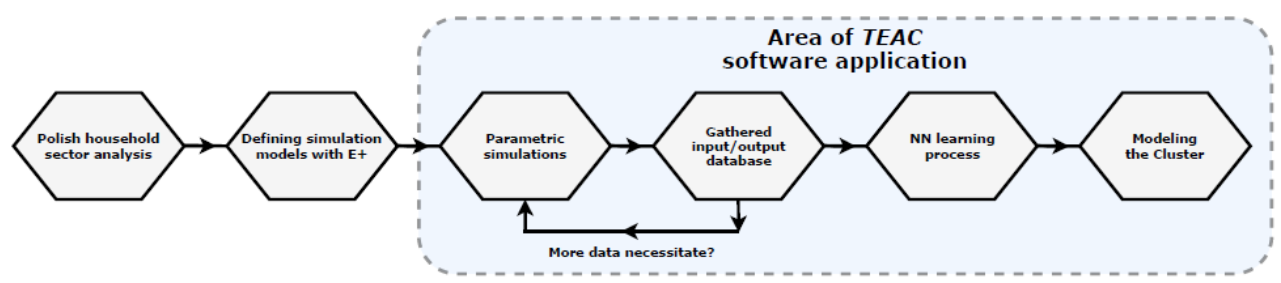

Fig. 4. The analysis procedure schema with TEAC software application (own study)

Furthermore, it is possible to define into TEAC software some technical parameters of commercially used PV modules or additional wind turbines.

The potential electricity production of PV installations located at available roofs areas might be analysed. PV installation is automatically defined dependent on the building type and its orientation (roofs slopes oriented North, North-East or North-West are not included). A number of PV panels possible to install are calculated based on available area and average PV module dimensions (avoiding overestimating of installation size). The potential electricity production is calculated using isotropic radiation model [19] and standard characteristics of PV panels with efficiency approx. 18.8\% [20].

The potential electricity production using onshore or offshore wind turbines might be calculated. Electricity production out of the wind is based on converting the kinetic energy of wind into mechanical energy [21]. According to Betz's law, wind turbines have limitations in energy convert - theoretical limit of the maximum power coefficient $\left(\mathrm{C}_{\mathrm{p}}\right)$ is 0.59 . In fact, there are some additional declinations of $\mathrm{C}_{\mathrm{p}}$ value - caused by i.a. rotation of the wake behind the rotor or aerodynamic drag [21]. Practically, including all variables affecting $C_{p}$ value, it ranges between 0.35 and 0.45 . Electricity production from wind turbines application was calculated using equation (1) and (2). The data of wind speed time distribution for onshore calculations were obtained from weather data (TMY files), while for offshore ones from the FINO2 research platform records (which is located $33 \mathrm{~km}$ North of the island Rugen - Germany) [22]. Within the performed study, two commercially available wind turbines (one for onshore and one for offshore application) were used - their main technical data [22] are presented in Table 2.

$$
\begin{gathered}
P_{\text {avail }}=\frac{1}{2} \cdot \rho \cdot A \cdot V^{3} \cdot C_{p} \\
V_{h}=V_{0} \cdot\left(\frac{h}{h_{0}}\right)^{\alpha}
\end{gathered}
$$

where:

$\mathrm{P}_{\text {avail }}$ - available power $[\mathrm{MW}]$

$\rho-$ air density $\left[\mathrm{kg} / \mathrm{m}^{3}\right]$

A - the swept area of the turbine $\left[\mathrm{m}^{2}\right]$

$\mathrm{V}$ - wind speed $[\mathrm{m} / \mathrm{s}]$

$\mathrm{C}_{\mathrm{p}}$ - power coefficient [-]

$\mathrm{V}_{\mathrm{h}}$ - wind speed at rotor level $[\mathrm{m} / \mathrm{s}]$

$\mathrm{V}_{0}$ - wind speed at measurement height $[\mathrm{m} / \mathrm{s}]$

$\mathrm{h}-$ rotor height $[\mathrm{m}]$

$\mathrm{h}_{0}-$ measurement height $[\mathrm{m}]$

$\alpha-$ area roughness coefficient [-]
The final module of TEAC software allows us to present the results of the analysed neighbourhood. All obtained results might be presented as a tabular summary, figures or maps. Some exemplary results obtained by means of TEAC software are presented further in this article (see chapter 4).

TEAC software has a crucial advantage in the accuracy of the energy-related results over other softwares used for whole areas analyses. Moreover, used definitions of singular buildings consider more technical parameters - it is possible to implement new types of objects within the TEAC database. Another advantage of the computer tool is its flexibility in presenting results. All the mentioned above indicates that TEAC software is a special tool dedicated to energy-related analyses of some larger areas/regions.

Table 2. Technical parameters comparison of wind turbines used during performed analysis (source: [23])

\begin{tabular}{|c|c|c|}
\hline \multirow{2}{*}{ Datasheet } & \multicolumn{2}{|c|}{ Turbine model } \\
\cline { 2 - 3 } & V164-8.0 & Ge 1.6-100 \\
\hline Company & Vestas & Gen.Electric \\
\hline Destiny & offshore & onshore \\
\hline Rated power $[\mathbf{k W}]$ & 8000 & 1600 \\
\hline Hub height $[\mathbf{m}]$ & 100 & 100 \\
\hline Rotor diameter $[\mathbf{m}]$ & 164 & 100 \\
\hline Cut-in wind sp. $[\mathbf{m} / \mathbf{s}]$ & 4.0 & 3.5 \\
\hline Rated wind sp. $[\mathbf{m} / \mathbf{s}]$ & 13.0 & 11.0 \\
\hline Cut-out wind $\mathbf{s p} .[\mathbf{m} / \mathbf{s}]$ & 25.0 & 25.0 \\
\hline Survival wind $\mathbf{s p .}[\mathbf{m} / \mathbf{s}]$ & 50.0 & no data \\
\hline
\end{tabular}

\subsection{Preliminary analysis}

In this section, some results concerning energy profiles for the Polish representative single-family houses are presented. The building energy consumptions are related to their energy characteristics. Each of the analysed houses was characterized by a different set of buildings parameters. In Polish climatic conditions, it is necessary to use (ensure?) heating during the winter period in order to guarantee appropriate interior conditions for residents. The simulations were performed with an hourly calculation step, nevertheless, they are presented as monthly averaged ones - for better readability. In Fig. 5 monthly heating energy consumptions per area of the analysed buildings are presented. As expected, the older the building, the more heating energy it consumes per area. Additionally, the time evolution of heating energy

*Corresponding author: marcin.zygmunt@p.lodz.pl 
demand for an extreme winter week in Lodz is shown in Fig. 6. The selected week was characterized by the lowest temperatures of the year - parallel with the highest heating demands. It can be seen, that heating demand for more efficient houses, with better thermal parameters of the building enclosure, is more uniform. Moreover, energy profiles of modern buildings have smaller daily amplitudes of heating demand with lower peak values.

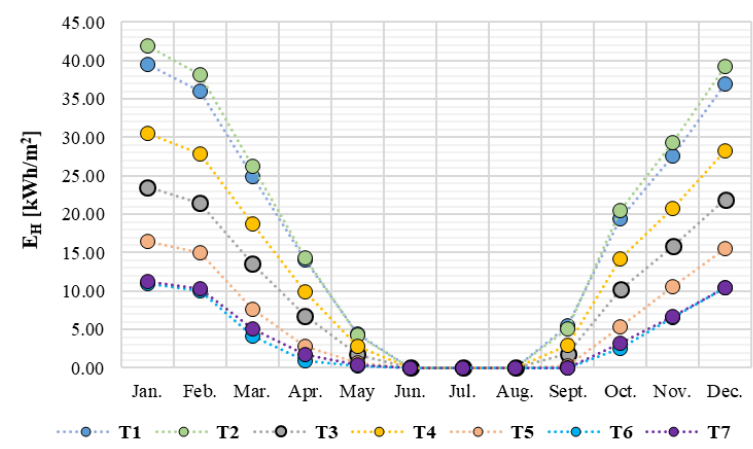

Fig. 5. Monthly total heating consumption per area - buildings models comparison

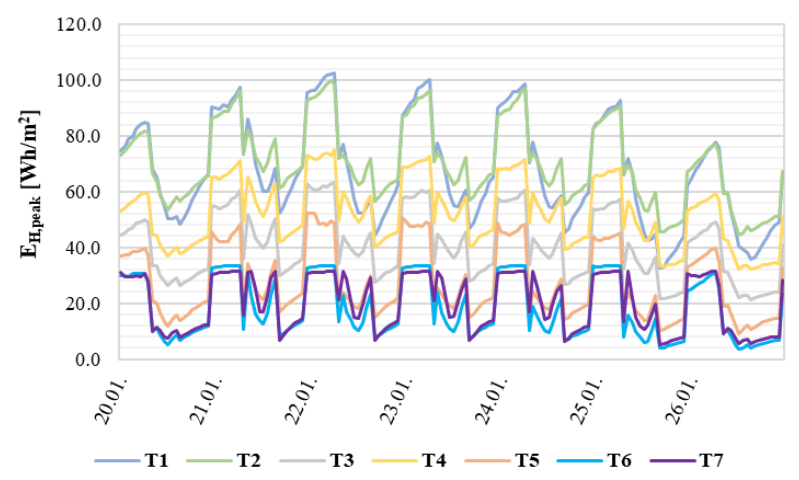

Fig. 6. Heating energy distribution for extreme winter week buildings models comparison

From the presented exemplary results it can be concluded, that buildings refurbishment in Poland has a great potential for overall energy efficiency improvement. The energy profile of single-family houses become more even and the total energy consumption is much lower.

\section{Case study}

For purposes of the performed analysis, a neighbourhood consisting of 10 thousand single-family houses is defined with dimensions of $100 \times 100$ building plots. It is assumed, that each building is located directly in the centre of a square plot, $30 \mathrm{~m} \times 30 \mathrm{~m}$ and all available plots are occupied. Also, buildings orientations are random, varying by 45 degrees. The above-defined area was analysed by means of TEAC software. Two localizations are examined: Leba (Polish seashore city) and Lodz (a city in central Poland). The second schema of area structure type (DT2 in Fig. 3b) is used. It is assumed, that the analysed neighbourhood has an old centre, consisted of $3.2 \mathrm{~K}$ houses, built before 1945 . The neighbourhood buildings space distribution can be seen in Fig. 7. A brief summary of the results for the neighbourhood located in Leba is presented in Table 3. The buildings of type T1 (see Table 1) due to their high number within the analysed neighbourhood and their poor thermal properties are characterized with highest heating energy consumption as well as $\mathrm{CO}_{2}$ emission. The newer the building group, the lower annual heating energy consumption and $\mathrm{CO}_{2}$ emissions are observed. This may be explained by both less number of those buildings and their better thermal properties. Electricity consumption (both by lighting and electrical equipment) is a linear function, dependent on a building area. Emissions were calculated based on heating and electricity consumptions as well as fuels used for energy production purposes.

The main goal of the performed study was to examine potential energy efficiency improvement of the analysed neighbourhood by application of advanced buildings refurbishment for two Polish locations: Leba and Lodz. Unfortunately, due to paper length limitation, the detailed results obtained by means of TEAC software are presented for Leba only. The proposed approach of local energy efficiency improvement might be considered as an Energy Cluster. The considered refurbishment variants are:

- Decrease of the $U$-value of exterior walls $\left(U_{w}\right)$ to $0.20\left[\mathrm{~W} / \mathrm{m}^{2} \mathrm{~K}\right]$ due to ETICS application,

- Decrease of the U-value of roofs $\left(\mathrm{U}_{\mathrm{r}}\right)$ to 0.15 $\left[\mathrm{W} / \mathrm{m}^{2} \mathrm{~K}\right]$ due to additional thermo-insulation,

- Decrease of the $U$-value of ground floors $\left(U_{\mathrm{gf}}\right)$ to $0.30\left[\mathrm{~W} / \mathrm{m}^{2} \mathrm{~K}\right]$ due to additional thermal insulation,

- buildings fenestration replacement with tripleglazed windows, with $\mathrm{U}$-value $\left(\mathrm{U}_{\text {win }}\right)$ equal to $0.90\left[\mathrm{~W} / \mathrm{m}^{2} \mathrm{~K}\right]$,

- replacement of heating stove with the one supplied with natural gas resulted in heating system COP improvement up to $87 \%$,

- replacement of traditional lightbulbs with LEDs.

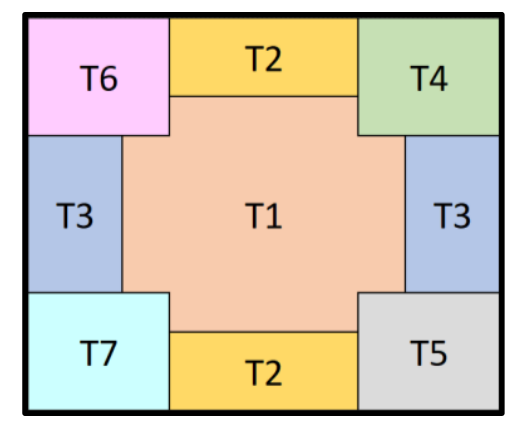

Fig. 7 Schematic plan of the analysed neighbourhood

Also, some additional analyses were performed apart, based on buildings parameters and their energy demand. Within final results we can observe:

- load duration curves of heating and electricity demands of the analysed area before and after buildings refurbishment (see Fig. 9),

- comparison of maps before and after buildings refurbishment, representing: 
- annual heating energy consumption per buildings area (see Fig. 10a and 10b),

- emissions by means of $\mathrm{CO}_{2}$ (Fig. 10c and 10d),

- renewables potential of solar and wind energy usage (see Fig. 11).

Table 3. Brief results summary for the defined neighbourhood

\begin{tabular}{|c|c|c|c|c|}
\hline $\begin{array}{c}\text { Building } \\
\text { type }\end{array}$ & Amount & $\begin{array}{c}\mathbf{E}_{\mathbf{H}} \\
{[\mathbf{M W h} / \mathbf{a}]}\end{array}$ & $\begin{array}{c}\mathbf{E}_{\mathbf{E}} \\
{[\mathbf{M W h} / \mathbf{a}]}\end{array}$ & $\begin{array}{c}\mathbf{C O}_{\mathbf{2}} \\
\text { emiss. } \\
{[\mathbf{t} / \mathbf{a}]}\end{array}$ \\
\hline \multirow{2}{*}{ T1 } & $\begin{array}{c}3200 \\
(32 \%)\end{array}$ & $\begin{array}{c}90307.96 \\
(36.41 \%)\end{array}$ & $\begin{array}{c}22731.81 \\
(20.33 \%)\end{array}$ & $\begin{array}{c}40927.21 \\
(32.91 \%)\end{array}$ \\
\hline \multirow{2}{*}{ T2 } & 1600 & 59923.38 & 14544.97 & 26938.37 \\
& $(16 \%)$ & $(24.16 \%)$ & $(13.01 \%)$ & $(21.66 \%)$ \\
\hline \multirow{2}{*}{ T3 } & 1600 & 43489.22 & 19970.63 & 23372.79 \\
$(16 \%)$ & $(17.53 \%)$ & $(17.86 \%)$ & $(18.79 \%)$ \\
\hline \multirow{2}{*}{ T4 } & 900 & 23055.12 & 11668.64 & 9394.60 \\
& $(9 \%)$ & $(9.29 \%)$ & $(10.44 \%)$ & $(7.55 \%)$ \\
\hline \multirow{2}{*}{ T5 } & 900 & 12323.52 & 12867.69 & 7713.63 \\
& $(9 \%)$ & $(4.97 \%)$ & $(11.51 \%)$ & $(6.20 \%)$ \\
\hline \multirow{2}{*}{ T6 } & 900 & 8877.69 & 14375.77 & 7629.86 \\
& $(9 \%)$ & $(3.58 \%)$ & $(12.86 \%)$ & $(6.14 \%)$ \\
\hline \multirow{2}{*}{ T7 } & 900 & 10076.2 & 15638.41 & 8384.59 \\
$(9 \%)$ & $(4.06 \%)$ & $(13.99 \%)$ & $(6.74 \%)$ \\
\hline
\end{tabular}

Where: $\mathbf{E}_{\mathbf{H}}$ : annual heating energy consumption $[\mathrm{MWh} / \mathrm{a}]$; $\mathbf{E}_{\mathbf{E}}$ : annual electricity consumption $[\mathrm{MWh} / \mathrm{a}]$, emiss.: $-\mathrm{CO}_{2}$ emission [t/a]

\section{Results}

The analysed neighbourhood consists of 10 thousand single-family houses, representative for the Polish household sector. Obtained results were presented as a comparison between areas located in Lodz and Leba, as well as the comparison of selected results, for buildings and their installations before and after refurbishment.

In Fig. 8. one can see a summary of the results for the analysed area, for both locations, and for the houses before and after modernization. It may be observed, that for Leba total heating and electricity consumptions are higher compared to Lodz. After considered buildings modernization, heating demand decreases by approx. $79.6 \%$ for both locations, while electricity consumption drops respectively by $35.2 \%$ and $33.6 \%$ for $\mathrm{Lodz}$ and Leba. Energy demand decrease resulted in limiting $\mathrm{CO}_{2}$ emissions - the amount of emitted $\mathrm{CO}_{2}$ drops by approx. $68 \%$ for both localizations.

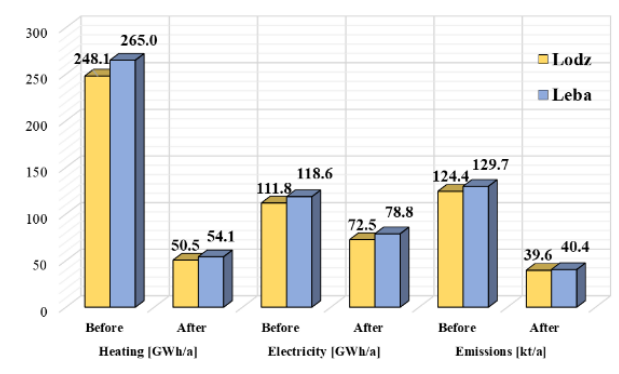

Fig. 8. Comparison of total heating and electricity consumptions and emissions of analysed neighbourhood
Load Duration Curve (LDC) is another way to present results obtained by means of TEAC software. LDC distribution is crucial for local electrical grid analysis and appropriate energy management of the region. Presented graph (Fig. 9.) is a comparison of scenarios before and after buildings refurbishment, for heating and electricity demand, for both analysed locations. Proposed modernizations result in a significant decrease in peak demands, especially for heating purposes - peak demand dropped by $78.3 \%$. Moreover, demand distribution is much more uniform for the modernized neighbourhood. Finally, after the modernizations, a slight decrease in the duration of the heating period is observed.

Another way to present results by means of $T E A C$ software are maps of the analysed area. Each cell represents a single building within a defined area. In Fig. 10 a comparison of the results for an analysed neighbourhood located in Leba can be seen, for scenarios before and after modernizations. In presented maps, heating energy consumption per building area and $\mathrm{CO}_{2}$ emissions outputs are shown.

In the presented study a RES potential is analysed by comparing it with the electricity demand of the neighbourhood. Solar (by means of PV installations) and wind (onshore and offshore wind turbines potential) energy are examined in two different climatic conditions. In the performed study, an impressive amount of 215167 PV panels was assumed on the available houses roof slopes. Without the addition of advanced energy storage systems, proposed PV installations are capable to cover approx. $17.6 \%$ of the actual, timely distributed electricity demand of the analysed neighbourhood. Considering fully usage of produced electricity, PV installations are capable to cover $65.7 \%$ of electricity demand. Solar energy usage is even higher considering resale of an over plus production or application of storage systems. Wind energy analysis was performed by means of potential electricity production for two scenarios: onshore (two localizations: Lodz and Leba) and offshore (Baltic sea). The number of applied wind turbines was calculated based on peak electricity demand of analysed neighbourhood and technical parameters of the assumed turbines. The peak electricity demand is equal to $36174.41 \mathrm{~kW}$, logged for $1^{\text {st }}$ January, at 5 PM. During that time, a single offshore wind turbine is capable to generate $8000 \mathrm{~kW}$ energy, while onshore wind turbines $1600 \mathrm{~kW}$ and $1180 \mathrm{~kW}$, accordingly for Leba and Lodz wind conditions. Approximate amount of necessary wind turbines capable to cover the electricity demand of the analysed neighbourhood scenarios is 5 for offshore, 23 for Leba and 31 for Lodz. The potential electricity distributions of RES applications are shown in Fig. 11, for typical winter (20-26 January) and summer (15-21 August) weeks.

\section{Summary and conclusions}

The performed study aimed to examine energy and ecologic efficiency of a residential neighbourhood by means of home developed computer tool TEAC. It turned out, that TEAC software application is a suitable approach 
for Polish household sector analyses. Additionally, the developed tool uses ANN for heating demand prediction with sufficient accuracy compared with validation outputs obtained by means of Energy Plus software.

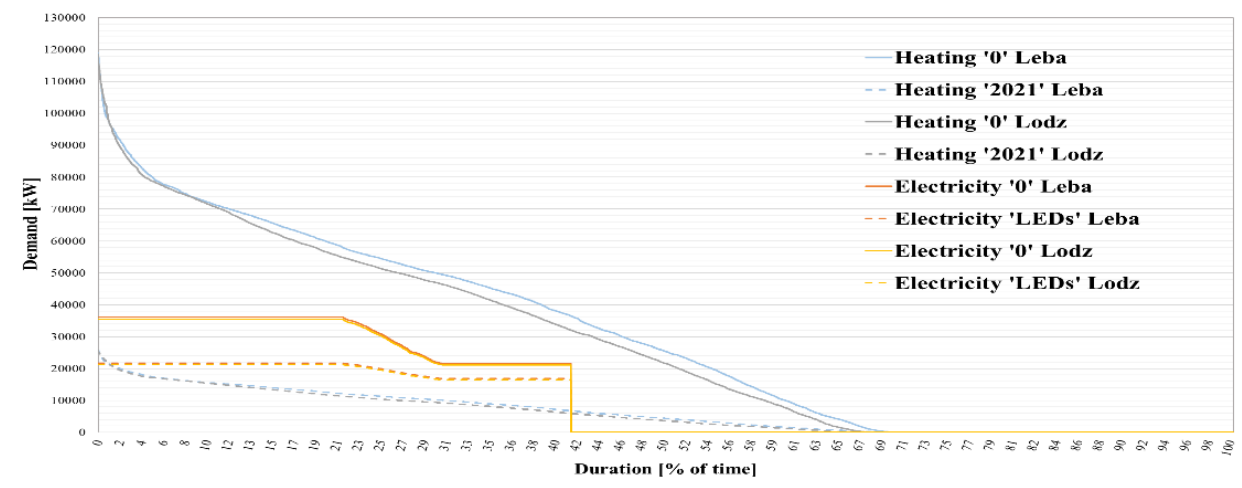

Fig. 9. Load duration curves of analysed neighbourhood - heating \& electricity demand for various scenarios

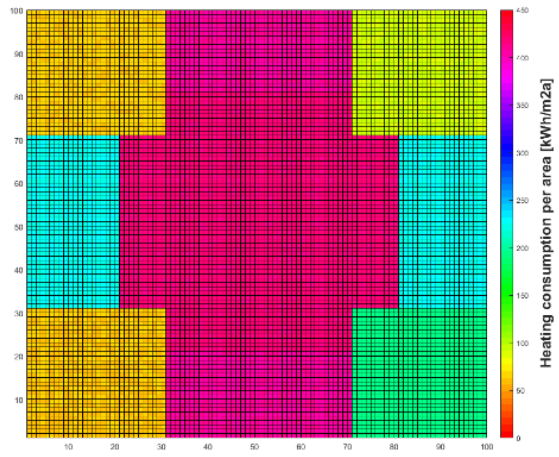

(a)

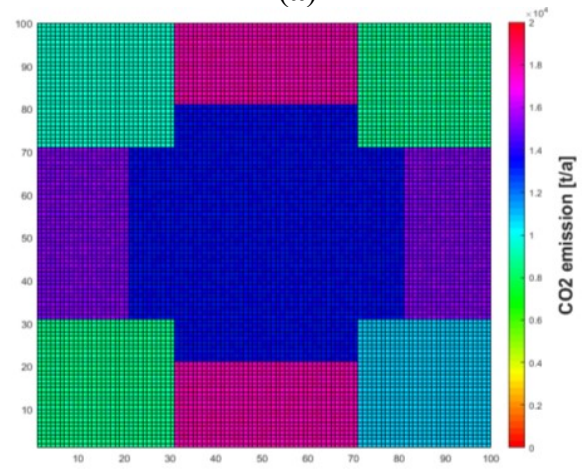

(c)

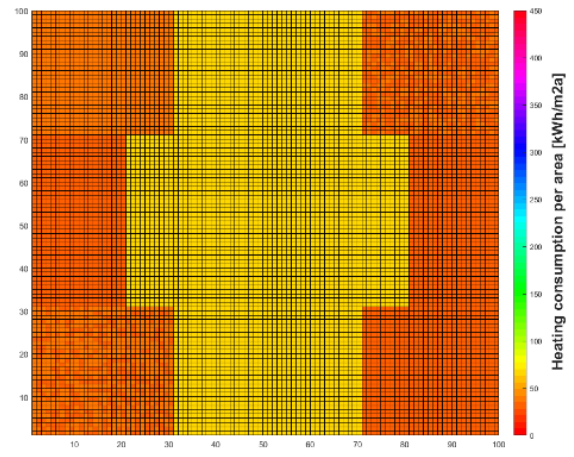

(b)

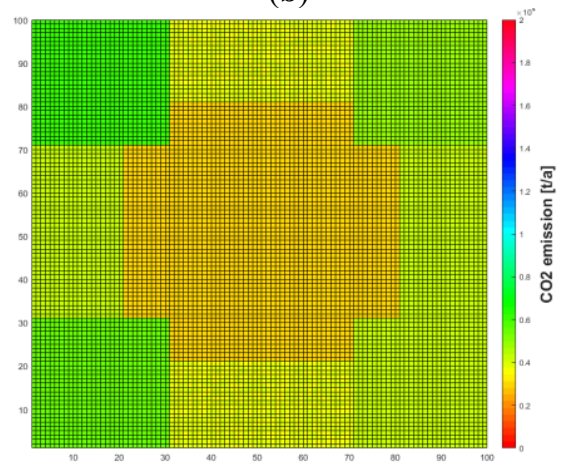

(d)

Fig. 10. The result maps for the analysed neighbourhood: heating energy consumption per area - base variant (a) and after thermal renovation (b); annual $\mathrm{CO}_{2}$ emission - base variant (c) an after modernizations (d) 


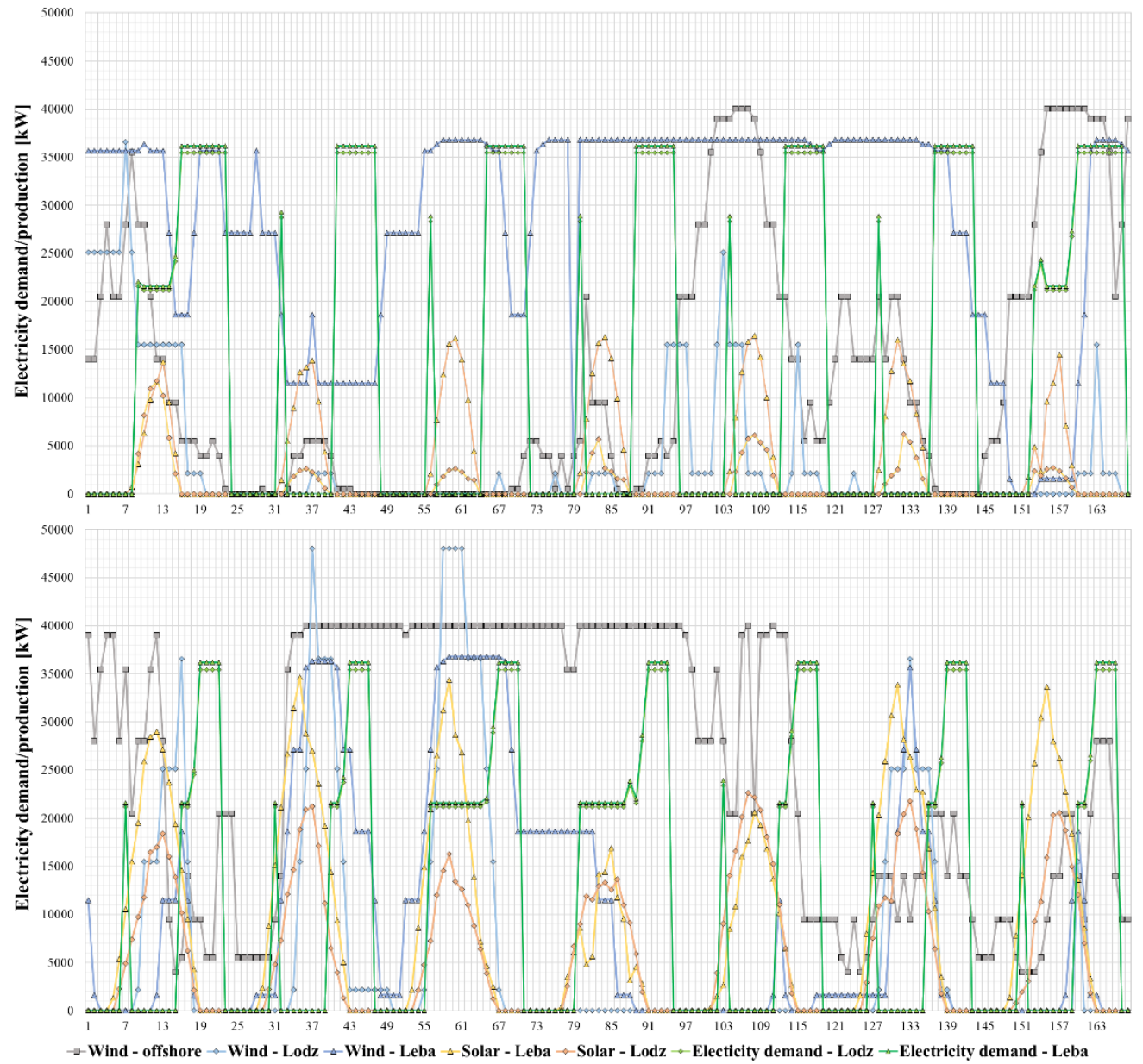

Fig. 11. RES application - potential electricity outputs using solar and wind energy - comparison with the electricity demand of analysed neighbourhood for typical winter (up) and summer (bottom) week.

$T E A C$ software offers flexibility in presenting results of various energy-related analyses. Those studies allow eliminating energy peaks and coordinate electrical grid management. Also, analyses of renewables application are likely field of $T E A C$ software usage. Energy-related analyses of residential areas, performed using the developed tool are agreeable with the EC paradigm.

During the analysis, a potential electricity production out of PV installations was performed. Calculations were based on available and favorable roofs slopes of singlefamily houses constituted analyzed area. Obtained results should be considered as an estimation - for each building, it is necessary to check the available roof area, as well as local shading. For the analyzed area, a total number of 215167 PV panels (approx. 21 panels per building) were applied. Applied PVs are capable to produce $39.6 \mathrm{GWh} / \mathrm{a}$ (34.3 GWh/a in Lodz) of electricity with peak output equal to 39.89 MW (36.84 MW in Lodz). It was observed, that Leba has higher solar potential than Lodz. Solar energy has a huge potential for buildings applications in Poland. Unfortunately, due to limited solar radiation occurrence during the day, it is difficult to maximize solar energy potential. Typically, the highest outputs energy produced out of sun occurs during low electricity demand for residential buildings, except weekends. The mentioned issue might be terminated by application of energy storages or connecting our solar installation into the grid - nevertheless, none of these was analysed in this paper. To fill up the PV application analysis, it is important to perform a detailed economic study, including the cost of installations, as well as potential income from the excess energy produced resold.

Offshore wind turbines, applied in Baltic sea area are much more efficient than onshore turbines for electricity generating. Out of analyzed locations, Leba climate is more adapted for wind turbines application than Lodz. It results from both: different technical parameters of offshore and onshore wind turbines, as well as wind speed time and space distributions. The performed analysis did not include losses due to energy distribution and transmission. For the analyzed neighbourhood, approx. amount of onshore wind turbines for covering peak electricity demand is equal to 23 ( 31 for Lodz) while only 5 offshore wind turbines are required. Proposed wind turbines are capable to produce $144.7 \mathrm{GWh} / \mathrm{a}(105.9$ $\mathrm{GWh} / \mathrm{a}$ in Lodz and 195.1 GWh/a offshore) of electricity.

Energy production by renewables is dependent on the stochastic climatic factors - it is impossible to perform an accurate forecast for long- or short-term periods. It is important to remember, that using renewables, a temporal lack of covering energy demand is possible. Detailed 
economic analysis of renewables application for the whole residential areas will be the aim of future research.

Thermal comfort analyses are very important for buildings sector studies. Guaranteeing suitable inner climate conditions (including good air quality) are frequently the most important part of buildings analysis. These kind of analyses are crucial for commercial buildings, while for the residential sector it is not as much important - usually, residents are capable to manage interior climate according to their own needs. Also, thermal comfort analysis might be a driving factor within financial profitability probes. In the performed study, the energy-related analyses of a model neighbourhood were the main goal - thermal comfort analyses for residential sector might be a great concept for future works.

Authors are planning some further developments of the software to obtain a universal, user-friendly tool for Polish household sector analyses. A major focus will be set on a Graphical User Interface (GUI) development in order to software dissemination.

\section{References}

1. Statistic Poland, https://stat.gov.pl/en/search/ (accessed on 12.2019)

2. G. Di Foggia, Heliyon 4, e00953 (2018)

3. National Energy Conservation Agency (NAPE), Polish building typology - TABULA - scientific report (2012)

4. EnergyPlus, https://energyplus.net (accessed on 12.2019)

5. Z. Ma, P. Cooper, D. Daly, L. Ledo, Energy Build. 55, 889-902 (2012)

6. S. Wang, Z. Ma, HVAC\&R 14, 3-32 (2007)

7. S. Karjalainen, Build. Environ. 44, 1237-1245 (2009)

8. R. G. Junker, A. G. Azar, R. A. Lopes, K. B. Lindberg, G. Reynders, R. Relan, H. Madsen, Appl. Energy 225, 175-182 (2018)

9. G.R. Aghajani, H.A. Shyanfar, H. Shayeghi, Energy 126, 622-637 (2017)

10. X. Zhang, M. Lovati, I. Vigna, J. Widen, M. Han, C. Gal, T. Feng, Appl. Energy 230, 1034-1056 (2018)

11. I. Vigna, R. Pernetti, W. Pasult, R. Lollini, SCS 38, 526-533 (2018)

12. M. Zygmunt, D. Gawin, Energies (to be published)

13. CitySim Software, https://www.epfl.ch/labs/leso/ transfer/software/citysci/ (accessed on: 12.2019)

14. City Energy Analyst, https://cityenergyanalyst.com (accessed on 12.2019)

15. C. Buratti, M. Barbanera, D. Palladino, Appl. Energy 120, 125-132 (2014)

16. J. Pascual, J. Barricarte, P. Sanchis, L. Marroyo, Appl. Energy 158, 12-25 (2015)

17. D. Marquardt, J. SOC. 11, 431-441 (1963)

18. A.S.O. Ogunjuyigbe, T.R. Ayodele, O.A. Akinola, Appl. Energy 171, 153-171 (2016)
19. D. Chwieduk, Solar Energy in Buildings (Academic Press, 2014)

20. ITRPV Committee, International Technology Roadmap for Photovoltaic - Results 2017 (2018)

21. J.F. Manwell, J.G. McGowan, A.L. Rogers, Wind energy explained (Wiley, 2011)

22. FINO 2 research platform, http://www.fino2.de/en/ (accessed on: 01.09.2019)

23. 4C offshore, http://www.4coffshore.com (accessed on 01.09.2019) 